\title{
Tyrrhenian Upper Waters in the Ustica Island (Marine Protected Area, Sicily, Italy)
}

\author{
Marilena Sanfilippo, Giuseppa Pulicanò, Antonio Manganaro, \\ Alessandra Reale, and Giuseppa Cortese \\ Department of Animal Biology and Marine Ecology, Messina University, Salita Sperone 31, 98166 Messina, Italy \\ Correspondence should be addressed to Marilena Sanfilippo, msanfilippo@unime.it
}

Received 26 September 2008; Revised 20 March 2009; Accepted 19 May 2009

Recommended by Joseph Bidwell

The Marine Protected Area (MPA) of Ustica was monitored for the hydrographic properties in the A zone of the reserve during the period from the autumn of 2001 to the winter of 2003. This study is also a part of a great triennal project (2001-2004) "Sistema Afrodite", that was carried out in all the MPAs instituted in Italy. The parameters examined were treated statistically to show their seasonal variability. Temperature, nitrate, phosphate, and chlorophyll a showed similar trends between winter 2002 and 2003 , while differences between winter 2002 and 2003 were noticed for salinity, dissolved oxygen, and silicate. It is postulated that the Atlantic current and eddies along its margin result in variation of the water characteristics in the MPA zone analyzed in this study.

Copyright ( 2009 Marilena Sanfilippo et al. This is an open access article distributed under the Creative Commons Attribution License, which permits unrestricted use, distribution, and reproduction in any medium, provided the original work is properly cited.

\section{Introduction}

MPAs are recognized as a main tool for accomplishing a broad spectrum of objectives related both to nature conservation and protection of key habitats and species, support of local communities and nature-based tourism $[1,2]$, and the sustainable management of fisheries [3-5]. Italian legislation $[6,7]$ stipulated the establishment of a series of more than 50 coastal and marine sites requiring protection, and 25 national MPAs have been created around the Italian coast by 2009 (Figure 1).

The Italian MPAs are multiple-use protected areas conventionally implemented according to three different protection levels [8], typically including one or more core zones (i.e., no-entry, no-take reserves).

Ustica was the first MPA instituted in Italy in 1991. It is a small volcanic island situated 36 miles off the north-west coast of Sicily (southern Tyrrhenian Sea, Italy; $10^{\circ} 43 / 43^{\prime \prime}$ E$38^{\circ} 42 \prime 20^{\prime \prime} \mathrm{N}$ ). The island of Ustica is the relict of a large volcanic edifice, which developed first submarine, then subaerial, during the Quaternary. The island is $248 \mathrm{~m}$ high a.s.l., and its base lies about $2000 \mathrm{~m}$ below sea level. The rocks of the islands are volcanic, except for a small sedimentary area on the western coast. The products of submarine volca- nic activity are mainly basalts [9]. Assemblages of photophilic algae, Posidonia oceanica beds, and coralligenous, concretions are the prevailing biotic communities [10]. Some areas of soft bottom exist, but these are restricted to small lenses of coarse and pebbles [11].

To assess the oceanographic features of the A zone of Ustica, we compared our data with some recent studies on the Mediterranean and its hydrographic characteristics [1214], and in particular a recent study [15] supported by the Commission Internationale pour l'Exploration Scientifique de la Mer Mediterranée (CIESM).

\section{Materials and Methods}

2.1. Study Area. Ustica MPA, established in 1986 and effectively running since 1991, encompasses a total area of 16000 ha and is divided into three zones with different levels of protection (Figure 2).

Zone A (about $60 \mathrm{ha}$ ), in the western part of the island, is a no-take area (or integral reserve) where only scientific research is permitted. Tourist swimming is restricted to two bays at the southernmost (Cala Acquario) and northernmost limits (Cala Sidoti) of the integral reserve. Local commercial fishing is permitted in zone B of the general reserve (about 


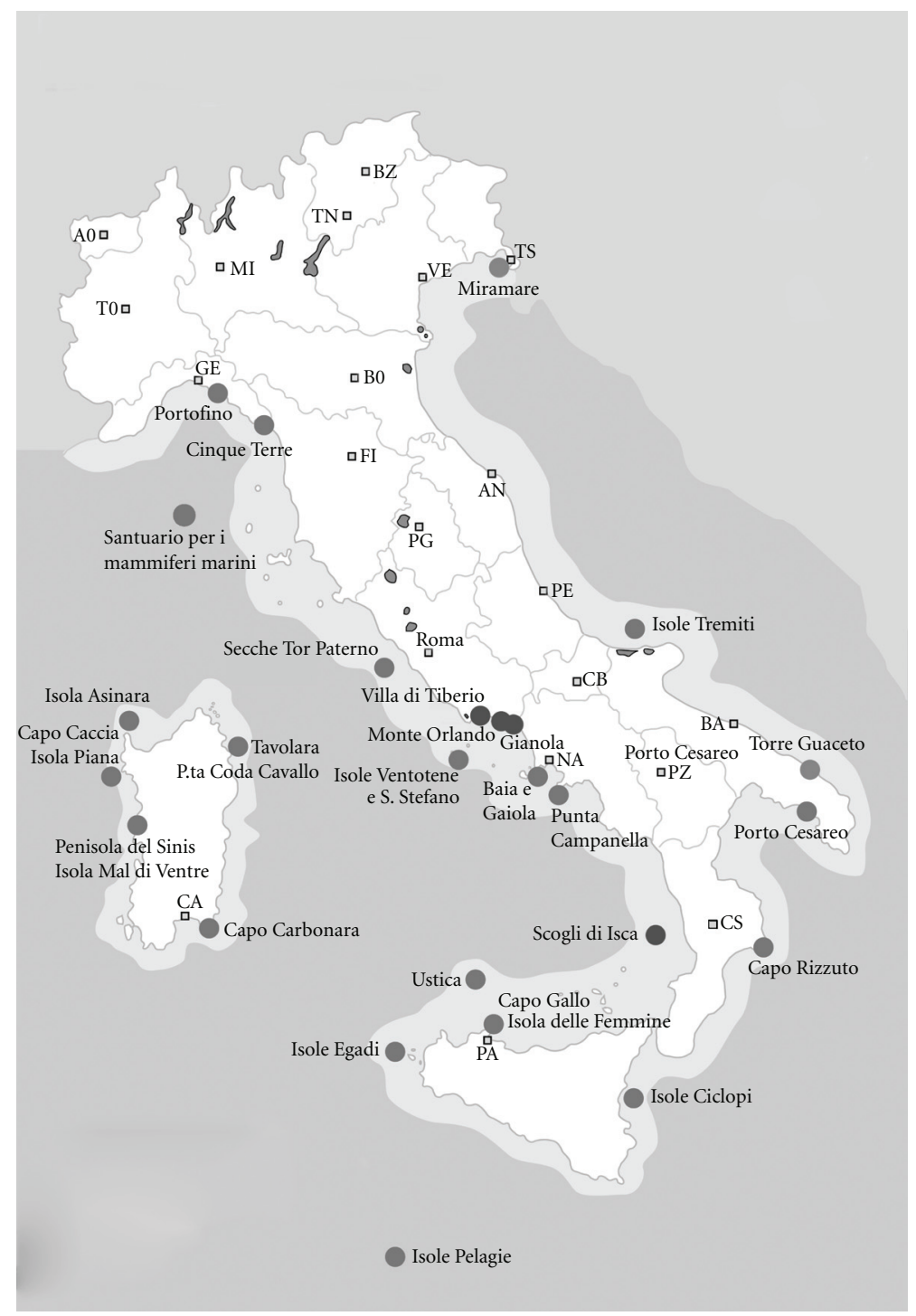

FIGURE 1: Italian MPAs updated to 2009 (redrawn from http://www.minambiente.it).

7860 ha, stretching along both sides of zone A) and zone C (about 8031 ha, in the southern part of the island from E-NE to SW) only $[16,17]$. There are no restrictions on recreational activities (i.e., scuba diving, boat anchoring, swimming, and angling) in both of these zones. Temporal data series indicating current levels of recreational uses at the site are largely unavailable [18].

2.2. Sampling and Analytical Methods. Each Italian MPA functions as a discrete entity at three key levels, administrative-institutional, socioeconomic, and scientific, reducing the opportunities for sharing efforts, resources, and experiences. ICRAM (Central Institute for the Research applied to the Sea), the lead marine research agency of the Italian government, conceived and financed a scientific research program, "Sistema Afrodite" [19], which was a first attempt at merging Italian MPAs into a national network for the specific purposes of standardizing scientific research, sharing information, and helping to improve the overall management of these areas. This triennial program (20012004) encompasses a number of coordinated activities, generally focused on the A zones (integral reserves). These activities included

(i) production of bathymetric, geomorphologic, and biocenotic maps for the A zones at $1: 2000$ scale;

(ii) monitoring of water column, phytoplankton, and sediments: sampled on a fortnightly schedule, according to Italian Legislation [20];

(iii) habitat and species inventory undertaken through the first nationwide application of standard data entry forms, developed within the framework of the Specially Protected Areas (SPA) Protocol of the Barcelona Convention [21];

(iv) fish visual censuses undertaken by scuba divers at 6 month intervals over a 2 -year period to collect quantitative data on fish abundance and size composition; 


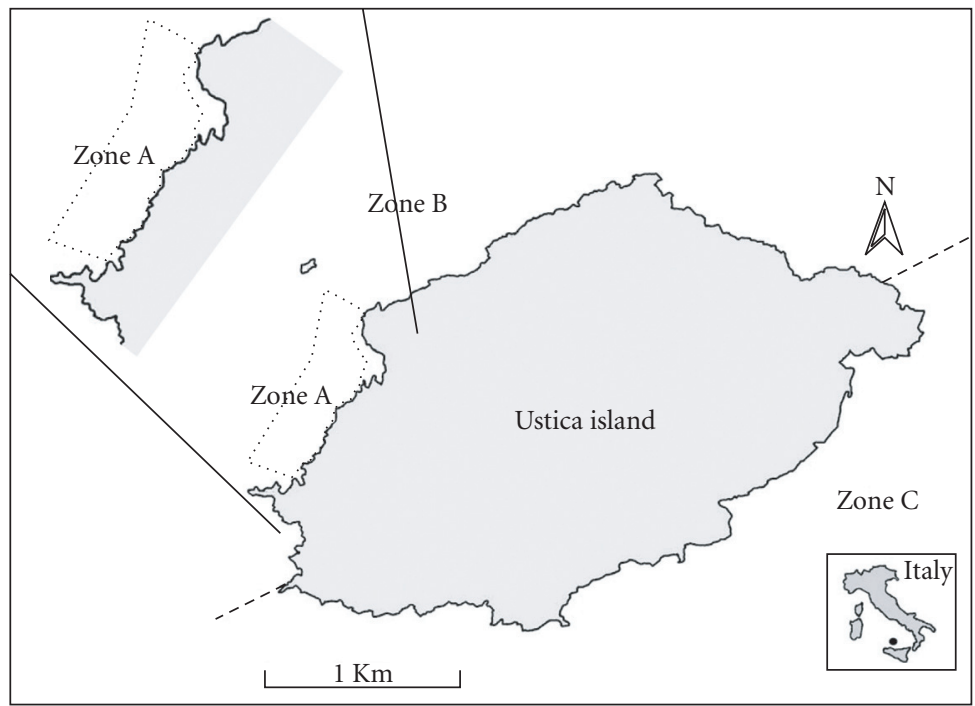

FIgURE 2: The zones of the Ustica marine protected area and the no-take area of the reserve.

(v) benthic sampling, by photographic and visual cover estimates every 6 months on hard-bottom benthos (subtidal zones) within the A zone, while two control samples are taken within zone B or C.

The location of the sampling stations in Ustica MPA, the fortnightly sequence, and the typology of analysis were established according to the same principles adopted in all the other MPAs surveyed within the National Project "Sistema Afrodite" [19] and according to the Italian Legislative Decree 152/99.

Water samples for our study were collected from September 13, 2001 to April 26, 2003 at 2 sampling stations (Figure 3) in the A zone.

The samples were collected using a Niskin bottle and carried out at 0 and $7 \mathrm{~m}$ depth in the station 1 and at $0,10,30$, and $40 \mathrm{~m}$ depth in the station 3 , according to bottom depths and to the directive of the Italian Legislative Decree 152/99. Hydrological data were collected with a salinometer YSI 80.

Samples for nutrients and chlorophyll $a$ were treated and analyzed according to Innamorati et al. [22].

The WinSTAT (2007.1) software was used for statistical treatment of the data. One way analysis of variance (ANOVA) was applied to the data to determine the presence of significant differences (Least Square Differences-LSD, significant level $P<.05)$ in the seasonally characteristics of sea waters.

\section{Results}

The TS diagram (Figure 4) summarizes the hydrographical characteristics of the waters sampled in the A zone of Ustica MPA during the whole period of observations (September 2001-April 2003).

The salinity shows values ranging from 36.9 to $38.5 \mathrm{PSU}$, while the temperature ranges from $14^{\circ} \mathrm{C}$ in winter to $29^{\circ} \mathrm{C}$ in summer. The bulk of salinity values lies between 37.5 and 38.0, a range typical of the southern Tyrrhenian Sea. The salinity values lower than 37.5 are associated to the Atlantic

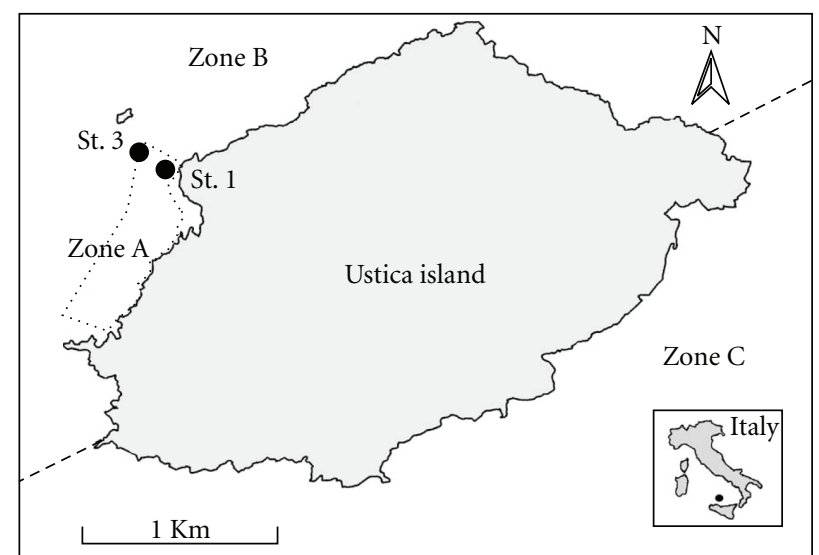

FIgURE 3: Sampling stations in Zone A.

Water mass, originating in the Western end of Mediterranean sea. Salinity greater than 38.0 indicates the influence of intermediate water masses such as Levantine Intermediate water (LIW) and Western Intermediate Water (WIW). But the dispersion of data on the TS diagram toward higher or lower values is associated to lower temperatures.

The salinity seasonal values (Figure 5), grouped in frequency classes, showed a larger variability in autumn and winter.

The salinity distribution differs also during the same season from year to year. Often the superficial layer sampled in the MPA of Ustica performed sudden changes of its hydrological characteristics from one sampling to another.

Similar trends were observed for concentrations of silicate (Figure 6), nitrate (Figure 7), and phosphate (Figure 8).

The concentration of phosphates showed a range from 1.57 to $0.05 \mu \mathrm{M}$. The bulk of values were smaller than $0.2 \mu \mathrm{M}$ in spring and in summer, but in fall and in winter the class of $0.3 \mu \mathrm{M}$ increased its weight. The classes higher than $0.5 \mu \mathrm{M}$ collect mainly autumn and winter values. 


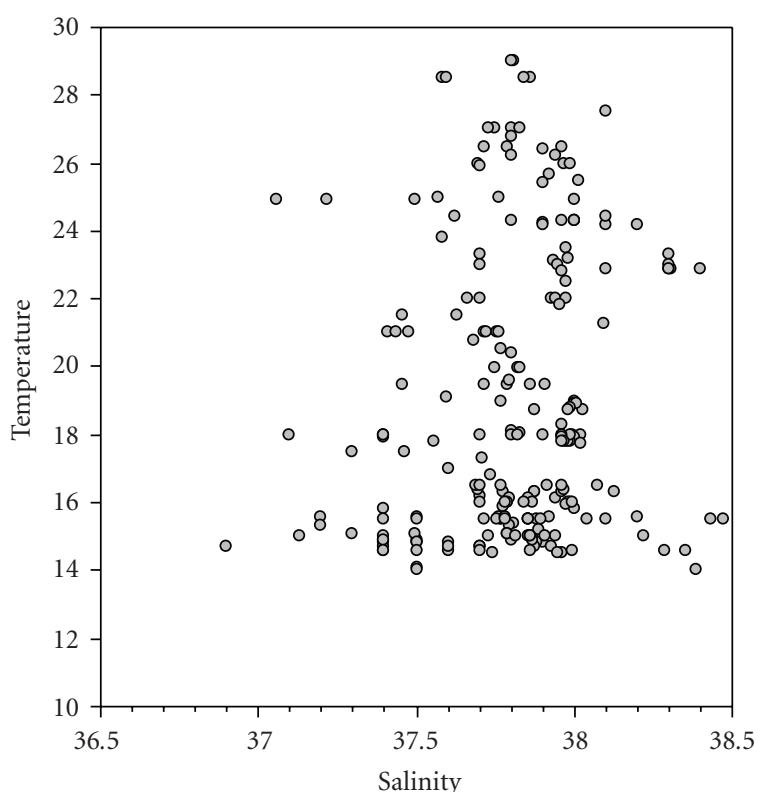

Figure 4: Temperature $\left({ }^{\circ} \mathrm{C}\right)$ versus salinity (PSU Units) relationship at the sampling stations (autumn 2001-winter 2003).

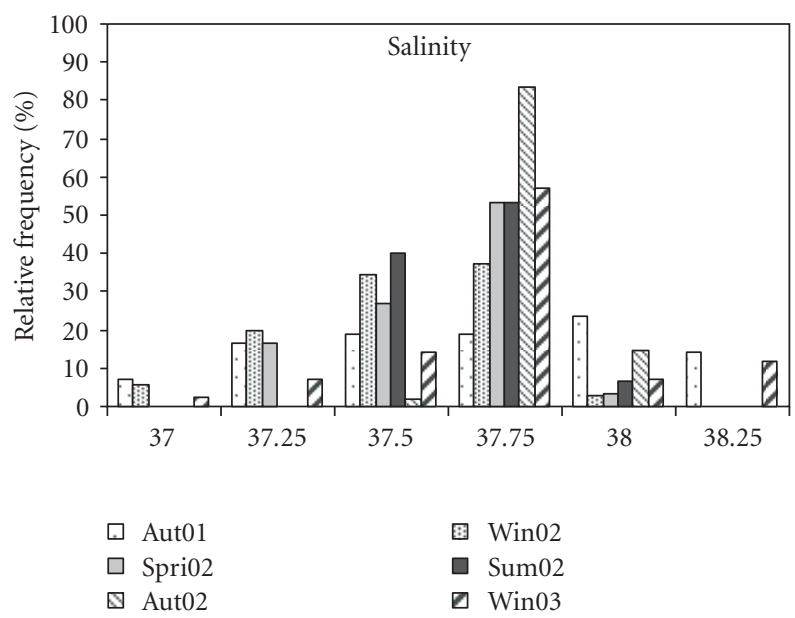

FIGURE 5: Salinity (PSU Units) seasonal distribution in frequency classes (autumn 2001-winter 2003). Labels report the class lower value.

Nitrate concentration ranged from 14.4 to 0.04 . The bulk of the values was smaller than $2.0 \mu \mathrm{M}$ for all the seasons, and autumn 2001 had $90 \%$ of its values in the first class.

Silicate concentrations ranged from 34 to $2.17 \mu \mathrm{M}$. Also for silicates the first class $(0-10 \mu \mathrm{M})$ collected the bulk of values, with the exception of spring 2002 and summer 2002 values, equally distributed in the smaller three classes.

Ranges for phosphate, nitrate, and silicate were within values identified by other authors in more recent surveys [23].

A natural shifting toward higher values in fall and in winter is to be expected, because of the mineralization processes into the upper layer of the water column and the increased vertical mixing after the destruction of the summer thermocline. Nevertheless in winter and autumn the

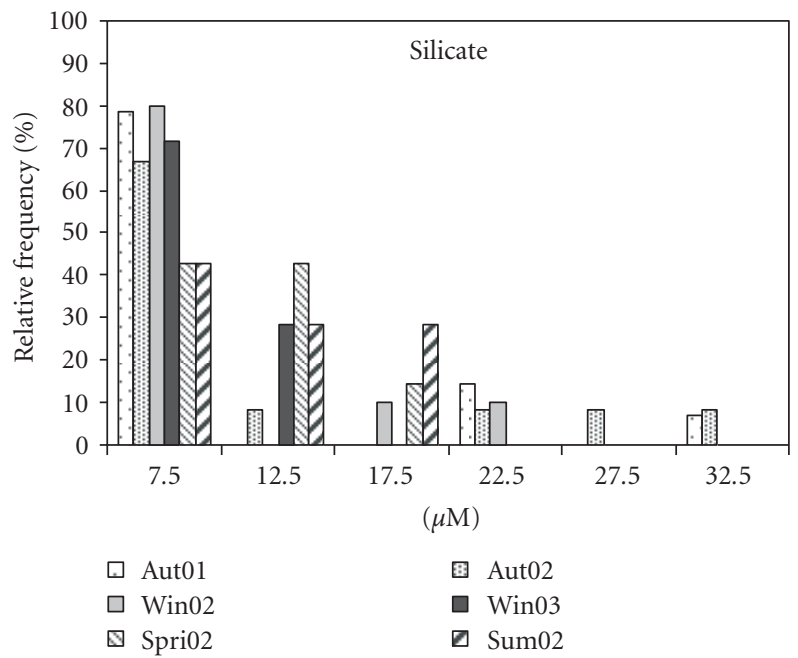

FIgURE 6: Silicate seasonal distributions in frequency classes (autumn 2001-winter 2003). Labels report the class lower value.

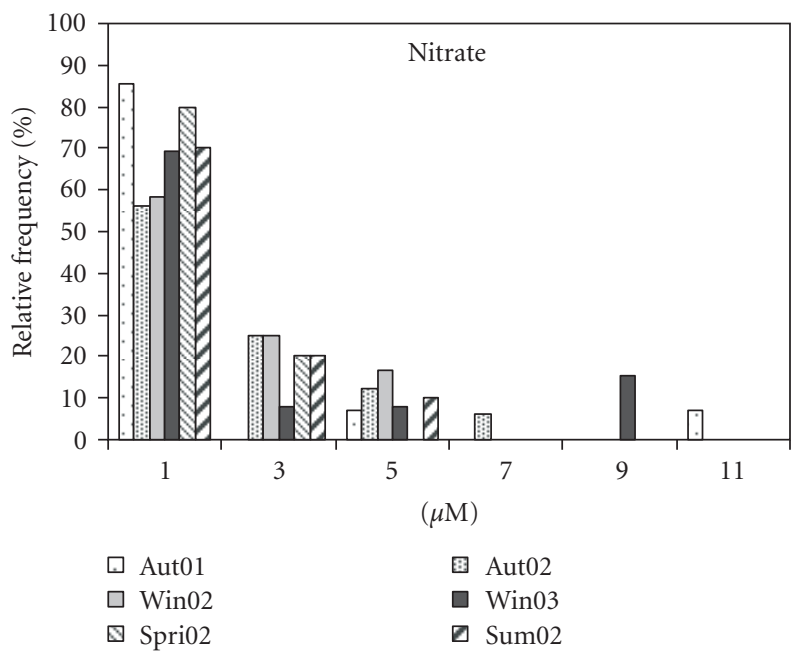

Figure 7: Nitrate seasonal distributions in frequency classes (autumn 2001-winter 2003). Labels report the class lower value.

higher classes of values show relative frequencies higher than expected.

In spring and in summer total chlorophyll $a$ values (Figure 9) are concentrated in the lower classes $(\leq 2 \mathrm{mg} / \mathrm{mc})$.

Concentrations as high as $11 \mathrm{mg} / \mathrm{mc}$ of Chlorophyll $a$ can be found in winter and autumn to a lesser extent.

The trend of higher mean values (Table 1) in winter and lower mean values in summer was observed for nitrate and phosphate. But the mean silicate value showed a peculiar trend decreasing from $10.77 \mu \mathrm{M}$ in winter 2002 to $6.18 \mu \mathrm{M}$ autumn 2002, maintaining a low level $(6.86 \mu \mathrm{M})$ even in winter 2003.

Seasonal mean value of the chlorophyll $a$ was as high as $5.8 \mathrm{mg} / \mathrm{mc}$ in winter 2002 and in winter 2003. The lowest mean value $(0.99 \mathrm{mg} / \mathrm{mc})$ was observed in summer 2002 .

The statistical treatment by ANOVA (Table 2) applied to the seasonal grouping of data for each parameter revealed similarities in the seasonal trend. Similar trend between 
TABLE 1: Mean values $(\boldsymbol{\mu})$, standard deviation $(\boldsymbol{\sigma})$, and number of samples $(\mathbf{n})$ for all examinated parameters.

\begin{tabular}{|c|c|c|c|c|c|c|c|}
\hline & & Autumn 2001 & Winter 2002 & Spring 2002 & Summer 2002 & Autumn 2002 & Winter 2003 \\
\hline \multirow{3}{*}{ Temperature $\left({ }^{\circ} \mathrm{C}\right)$} & $\mu$ & 20.46 & 15.01 & 18.06 & 24.72 & 20.40 & 15.76 \\
\hline & $\sigma$ & 4.09 & 0.38 & 2.13 & 3.32 & 3.52 & 0.98 \\
\hline & $n$ & 42 & 36 & 30 & 30 & 48 & 42 \\
\hline \multirow{3}{*}{ Salinity (PSU) } & $\mu$ & 37.81 & 37.62 & 37.74 & 37.76 & 37.94 & 37.88 \\
\hline & $\sigma$ & 0.35 & 0.26 & 0.17 & 0.11 & 0.08 & 0.28 \\
\hline & $n$ & 42 & 36 & 30 & 30 & 48 & 42 \\
\hline \multirow{3}{*}{ Dissolved oxygen $\left(\mathrm{mlL}^{-1}\right)$} & $\mu$ & 5.51 & 5.70 & 5.77 & 5.73 & 5.56 & 6.08 \\
\hline & $\sigma$ & 0.26 & 0.13 & 0.22 & 0.39 & 0.31 & 0.35 \\
\hline & $n$ & 37 & 36 & 30 & 29 & 47 & 40 \\
\hline \multirow{3}{*}{ Nitrate $(\mu \mathrm{M})$} & $\mu$ & 1.96 & 2.00 & 0.84 & 1.50 & 2.35 & 3.68 \\
\hline & $\sigma$ & 2.68 & 1.54 & 1.25 & 1.40 & 2.17 & 4.24 \\
\hline & $n$ & 14 & 12 & 10 & 10 & 16 & 14 \\
\hline \multirow{3}{*}{ Phosphate $(\mu \mathrm{M})$} & $\mu$ & 0.25 & 0.31 & 0.24 & 0.20 & 0.16 & 0.44 \\
\hline & $\sigma$ & 0.17 & 0.17 & 0.19 & 0.12 & 0.08 & 0.42 \\
\hline & $n$ & 14 & 12 & 10 & 10 & 16 & 14 \\
\hline \multirow{3}{*}{ Silicate $(\mu \mathrm{M})$} & $\mu$ & 10.77 & 12.42 & 9.46 & 7.11 & 6.18 & 6.86 \\
\hline & $\sigma$ & 8.90 & 8.61 & 5.36 & 3.51 & 4.26 & 5.22 \\
\hline & $n$ & 14 & 12 & 10 & 10 & 16 & 15 \\
\hline \multirow{3}{*}{ Chlorophyll $a(\mathrm{mg} / \mathrm{mc})$} & $\mu$ & 3.97 & 5.88 & 1.08 & 0.99 & 1.93 & 5.80 \\
\hline & $\sigma$ & 2.66 & 3.17 & 0.96 & 0.47 & 2.92 & 3.70 \\
\hline & $n$ & 37 & 36 & 30 & 29 & 41 & 29 \\
\hline
\end{tabular}

winter 2002 and 2003 data was observed for temperature, nitrate, phosphate, and chlorophyll $a$. Differences between winter 2002 and 2003 data were noticed for salinity, dissolved oxygen, silicate.

\section{Discussion and Conclusions}

The processing of data on the MPA of Ustica has revealed a differentiation not only in seasonal cycles but also between two successive yearly cycles. The heterogeneity observed for salinity, derived by TS diagram and by its distribution in the values classes, is a direct result of the movement of different water masses in the area. The silicates and dissolved oxygen trends are in agreement with that of salinity. Also these last two parameters are often used in the identification of water masses.

Geographically the island of Ustica is located on the route of a minor branch of the Atlantic Water, which travels to the surface through the channel of Sardinia and then along the northern coast of Sicily. Below the AW, the presence of Western Intermediate Water (WIW) is organized in subsurface isolate vortex [24] advected along the basin by the large-scale current. Like the Meddies in Atlantic Ocean, lenses of WIW are able to travel thousands of kilometers, preserving the identity of the source water. The Tyrrhenian basin is reached also by the Levantine Intermediate Water (LIW) coming by the Sicily channel and flowing along the Sicilian slope.

The overall cyclonic circulation in the Tyrrhenian coexists with several closed structures (gyres). In the surface eddies and gyre may be wind driven [25]. Presence of warm and cold structures, some permanent, other intermittent, was evidenced by satellite images [26] and by eXpendable Bathy-Thermographs (XBT) data analysis [14]. The smallscale mixing processes prevail over the large-scale ones. Topographic effects could be effective on deviating the currents and eddies trajectories, both on surface as on depth [15].

Moreover Gasparini et al. [13] have identified numerous interannual variations in the exchange of water masses between the southern Tyrrhenian Sea and the rest of the Mediterranean.

In our opinion, in the waters of the MPA of Ustica the variability over time for the parameters examined can to be considered associated with the transit of eddies along the edge of the Atlantic current that flows along the northern coast of Sicily. 
TABLE 2: One-way analysis of variance of seasonal variability of examinated parameters. Values in the same column with different letters are significantly different $(\mathbf{P}<.05)$.

\begin{tabular}{|c|c|c|c|c|c|c|c|}
\hline \multicolumn{8}{|c|}{ 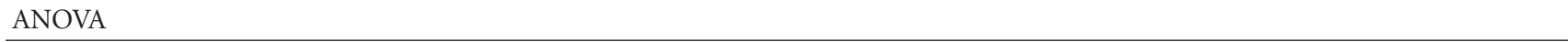 } \\
\hline \multirow{2}{*}{ ANUVA } & \multirow{2}{*}{$\begin{array}{c}\text { Temperature }\left({ }^{\circ} \mathrm{C}\right) \\
\mu \\
\end{array}$} & \multirow{2}{*}{$\begin{array}{c}\text { Salinity (PSU) } \\
\qquad \mu \\
\end{array}$} & \multirow{2}{*}{$\begin{array}{l}\text { oxygen } \\
\left(\mathrm{mlL}^{-1}\right) \\
\mu\end{array}$} & \multirow{2}{*}{$\begin{array}{c}\text { Nitrate }(\mu \mathrm{M}) \\
\qquad \mu \\
\end{array}$} & \multirow{2}{*}{$\begin{array}{c}\text { Phosphate }(\mu \mathrm{M}) \\
\mu \\
\end{array}$} & \multirow{2}{*}{$\begin{array}{c}\text { Silicate }(\mu \mathrm{M}) \\
\qquad \mu\end{array}$} & \multirow{2}{*}{$(\mathrm{mg} / \mathrm{mc})$} \\
\hline & & & & & & & \\
\hline Autumn 2001 & $20.46 c$ & $37.81 \mathrm{bc}$ & $5.51 \mathrm{a}$ & $1.96 \mathrm{ab}$ & $0.25 a$ & $10.77 \mathrm{ab}$ & $3.97 \mathrm{~b}$ \\
\hline Winter 2002 & $15.01 \mathrm{a}$ & $37.62 \mathrm{a}$ & $5.70 \mathrm{~b}$ & $2.00 \mathrm{ab}$ & $0.31 \mathrm{ab}$ & $12.42 b$ & $5.88 \mathrm{c}$ \\
\hline \multirow{2}{*}{$\begin{array}{l}\text { Spring } 2002 \\
\text { Summer } 2002\end{array}$} & $18.06 \mathrm{~b}$ & $37.74 b$ & $5.77 \mathrm{~b}$ & $0.84 a$ & $0.24 \mathrm{a}$ & $9.46 \mathrm{ab}$ & $1.08 \mathrm{a}$ \\
\hline & $24.72 \mathrm{~d}$ & $37.76 b$ & $5.73 b$ & $1.50 \mathrm{a}$ & $0.20 \mathrm{a}$ & $7.11 \mathrm{ab}$ & $0.99 a$ \\
\hline \multirow{2}{*}{$\begin{array}{l}\text { Autumn } 2002 \\
\text { Winter } 2003\end{array}$} & $20.40 c$ & $37.94 \mathrm{~d}$ & $5.56 \mathrm{a}$ & $2.35 \mathrm{ab}$ & $0.16 a$ & $6.18 \mathrm{a}$ & $1.93 \mathrm{a}$ \\
\hline & $15.76 \mathrm{a}$ & $37.88 \mathrm{~cd}$ & $6.08 c$ & $3.68 \mathrm{~b}$ & $0.44 \mathrm{~b}$ & $6.86 a$ & $5.80 \mathrm{c}$ \\
\hline
\end{tabular}

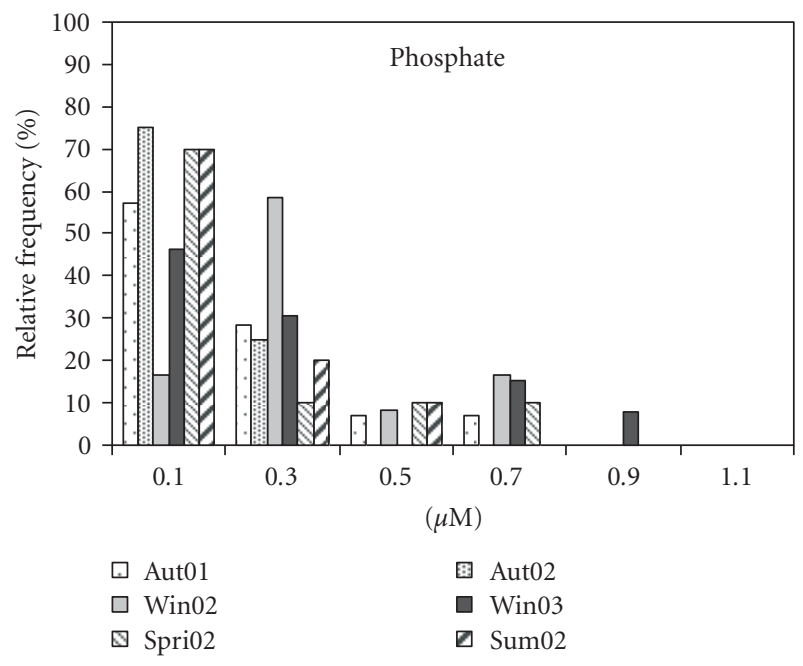

Figure 8: Phosphate seasonal distributions in frequency classes (autumn 2001-winter 2003). Labels report the class lower value.

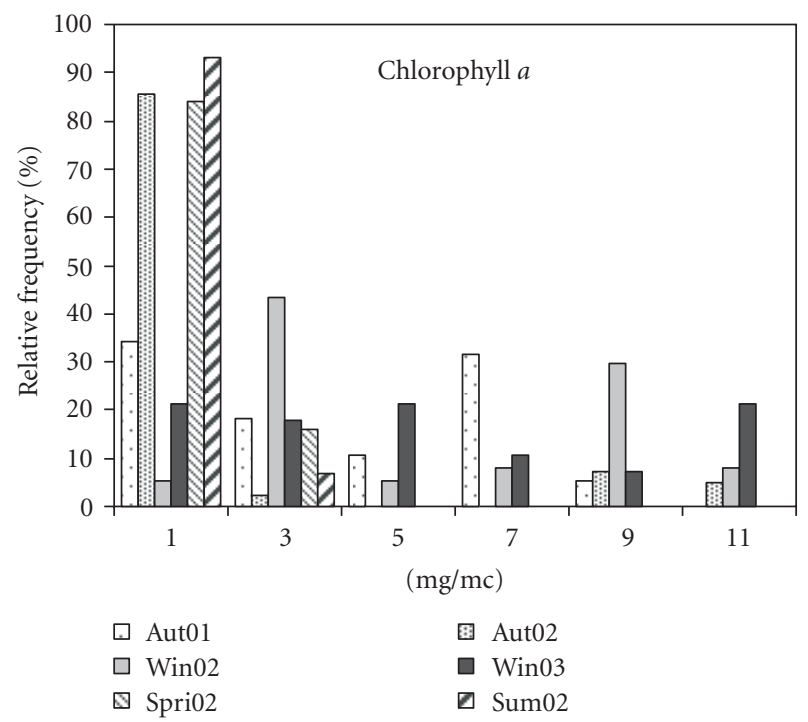

FIGURE 9: Chlorophyll $a$ seasonal distribution in frequency classes (autumn 2001-winter 2003). Labels report the class lower value.
The sampling strategy adopted for the investigation of MPA in the "system Aphrodite" is not suitable to detect this phenomenon in the case of Ustica. A different sampling strategy would make the island of Ustica a privileged point of observation to study the dynamics of eddies in the southern Tyrrhenian.

Finally, this study did not find a detectable human influence on the hydrological characteristics of the MPA, despite the increase in population due to tourism, which is recorded during the summer months $[27,28]$.

\section{Acknowledgments}

The authors are indebted to Ninì D'Angelo (fisherman of Ustica Island) and to Giovanni Maio (technician of Department of Animal Biology and Marine Ecology, Messina University) for their precious help during field work for the collection of samples. This study is part of a Doctoral thesis by M.S. and was funded by Afrodite Project of the Italian Ministry of the Environment.

\section{References}

[1] R. V. Salm, J. R. Clark, and E. Siirila, Marine and Coastal Protected Areas: A Guide for Planners and Managers, IUCN, Washington, DC, USA, 2000.

[2] P. F. J. Eagles, S. F. McCool, and C. D. A. Haynes, Sustainable Tourism in Protected Areas: Guidelines for Planning and Management, IUCN, Gland, Switzerland, 2002.

[3] S. N. Murray, R. F. Ambrose, J. A. Bohnsack, et al., "Notake reserve networks: protection for fishery populations and marine ecosystems," Fisheries, vol. 24, no. 11, pp. 11-25, 1999.

[4] T. Agardy, "Effects of fisheries on marine ecosystems: a conservationist's perspective," ICES Journal of Marine Science, vol. 57, no. 3, pp. 761-765, 2000.

[5] T. J. Ward, D. Heinemann, and N. Evans, The Role of Marine Reserves as Fisheries Management Tools: A Review of Concepts, Evidence and International Experience, Bureau of Rural Sciences, Canberra, Australia, 2001.

[6] Law no. 394/91, Legge quadro sulle Aree Protette, Official Gazette of Italian Republic no. 292/13-12-91/O.S.

[7] Law no. 979/82, Disposizioni sulla difesa del mare, Official Gazette of Italian Republic no. 16/18-1-83/O.S. 
[8] L. Tunesi and G. Diviacco, "Environmental and socio-economic criteria for the establishment of marine coastal parks," International Journal of Environmental Studies, vol. 43, pp. 253-259, 1993.

[9] S. Bellia, M. Brai, S. Hauser, P. Puccio, and S. Rizzo, "Natural radioactivity in a Volcanic Island: Ustica, Southern Italy," Applied Radiation and Isotopes, vol. 48, no. 2, pp. 287-293, 1997.

[10] M. Milazzo, R. Chemello, F. Badalamenti, and S. Riggio, "Molluscan assemblages associated with photophilic algae in the Marine Reserve of Ustica Island (Lower Tyrrhenian Sea, Italy)," Italian Journal of Zoology, vol. 67, no. 3, pp. 287-295, 2000.

[11] F. Andaloro, F. Fevola, M. T. Accardo-Palumbo, R. Lipari, and P. Pepe, "Cartografia morfologica e bionomica dei fondali dell'Isola di Ustica (Nord Sicilia)," in Proceedings of the 29th Società Italiana Biologia Marina, p. 78, Ustica, Italy, 1998.

[12] M. Astraldi, G. P. Gasparini, A. Vetrano, and S. Vignudelli, "Hydrographic characteristics and interannual variability of water masses in the central Mediterranean: a sensitivity test for long-term changes in the Mediterranean Sea," Deep-Sea Research Part I, vol. 49, no. 4, pp. 661-680, 2002.

[13] G. P. Gasparini, A. Ortona, G. Budillon, M. Astraldi, and E. Sansone, "The effect of the Eastern Mediterranean transient on the hydrographic characteristics in the Strait of Sicily and in the Tyrrhenian Sea," Deep-Sea Research Part I, vol. 52, no. 6, pp. 915-935, 2005.

[14] G. Fusco, G. M. R. Manzella, A. Cruzado, et al., "Variability of mesoscale features in the Mediterranean Sea from XBT data analysis," Annales Geophysicae, vol. 21, no. 1, pp. 21-32, 2003.

[15] G. Budillon, G. P. Gasparini, and K. Schroeder, "Persistence of an eddy signature in the central Tyrrhenian basin," Deep Sea Research Part II, vol. 56, no. 11-12, pp. 713-724, 2009.

[16] P. Gianguzza, M. Chiantore, C. Bonaviri, R. Cattaneo-Vietti, I. Vielmini, and S. Riggio, "The effects of recreational Paracentrotus lividus fishing on distribution patterns of sea urchins at Ustica Island MPA (Western Mediterranean, Italy)," Fisheries Research, vol. 81, no. 1, pp. 37-44, 2006.

[17] M. Milazzo, F. Badalamenti, G. Ceccherelli, and R. Chemello, "Boat anchoring on Posidonia oceanica beds in a marine protected area (Italy, western Mediterranean): effect of anchor types in different anchoring stages," Journal of Experimental Marine Biology and Ecology, vol. 299, no. 1, pp. 51-62, 2004.

[18] M. Milazzo, F. Badalamenti, T. Vega Fernández, and R. Chemello, "Effects of fish feeding by snorkellers on the density and size distribution of fishes in a Mediterranean marine protected area," Marine Biology, vol. 146, no. 6, pp. 1213-1222, 2005.

[19] S. Greco, G. N. Di Sciara, and L. Tunesi, “'Sistema Afrodite': an integrated programme for the inventorying and monitoring of the core zones of the Italian marine protected areas," Aquatic Conservation: Marine and Freshwater Ecosystems, vol. 14, supplement 1, pp. S119-S122, 2004.

[20] Legislative Decree no. 152/99, Disposizioni sulla tutela delle acque dall'inquinamento, Official Gazette of Italian Republic no. 177/30-7-1999/O.S. no. 146.

[21] UNEP, Mediterranean Action Plan and Convention for the Protection of the Mediterranean Sea against Pollution and Its Related Protocols, United Nations Environmental Programme, Athens, Greece, 1992.

[22] M. Innamorati, I. Ferrari, D. Marino, and M. Ribera D'Alcalà, "Metodi nell'ecologia del plancton marino," Nova Thalassia, vol. 11, p. 371, 1990.
[23] M. Ribera d'Alcalà, C. Brunet, F. Conversano, F. Corato, and R. Lavezza, "Nutrient and pigment distributions in the southern Tyrrhenian Sea during mid-summer and late fall 2005," Deep Sea Research Part II, vol. 56, no. 11-12, pp. 676-686, 2009.

[24] G. P. Gasparini, G. Zodiatis, M. Astraldi, C. Galli, and S. Sparnocchia, "Winter intermediate water lenses in the Ligurian Sea," Journal of Marine Systems, vol. 20, no. 1-4, pp. 319-332, 1999.

[25] S. Pierini and A. Simioli, "A wind-driven circulation model of the Tyrrhenian Sea Area," Journal of Marine Systems, vol. 18, no. 1-3, pp. 161-178, 1998.

[26] S. Marullo, R. Santoleri, and F. Bignami, "The surface characteristics of the Tyrrhenian Sea: historical satellite data analysis," in Seasonal and Interannual Variability of the Western Mediterranean Sea. Coastal and Estuarine Studies, vol. 46, pp. 135-154, AGU, Washington, DC, USA, 1994.

[27] F. Badalamenti, A. A. Ramos, E. Voultsiadou, et al., "Cultural and socio-economic impacts of Mediterranean marine protected areas," Environmental Conservation, vol. 27, no. 2, pp. 110-125, 2000.

[28] M. Milazzo, R. Chemello, F. Badalamenti, R. Camarda, and S. Riggio, "The impact of human recreational activities in marine protected areas: what lessons should be learnt in the Mediterranean sea?" Marine Ecology, vol. 23, supplement 1, pp. 280-290, 2002. 

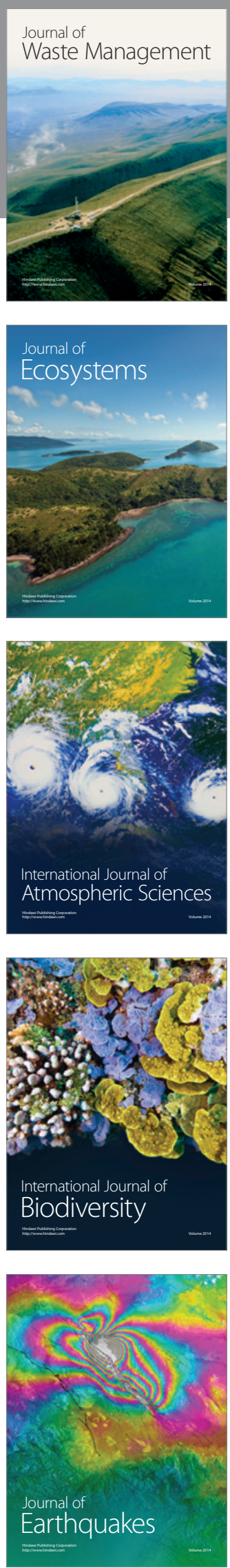
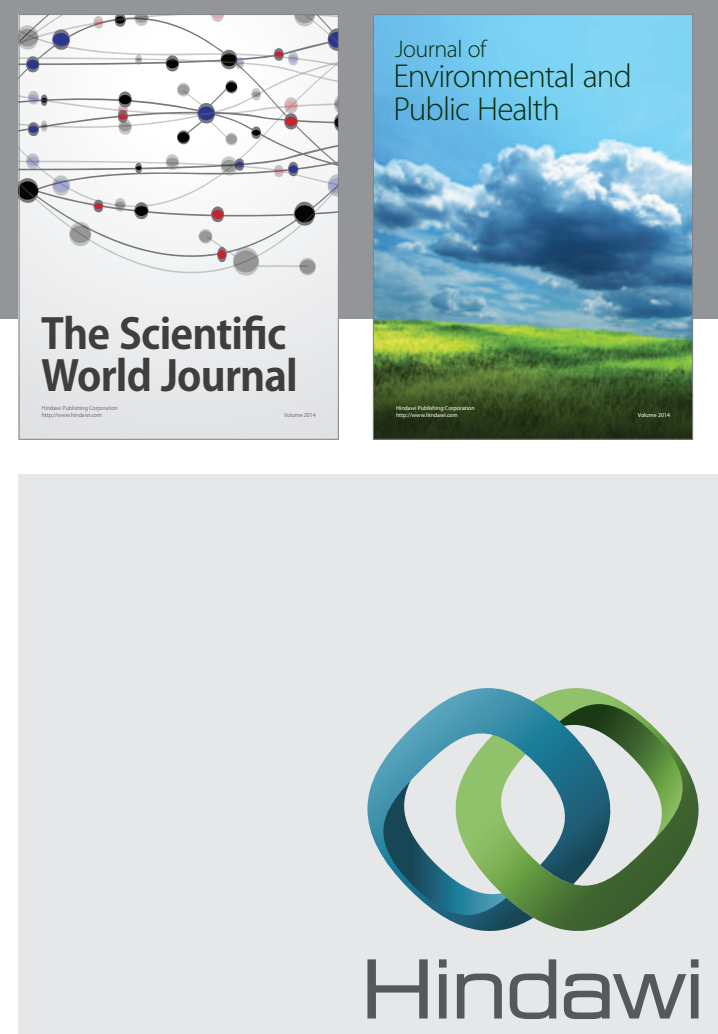

Submit your manuscripts at

http://www.hindawi.com
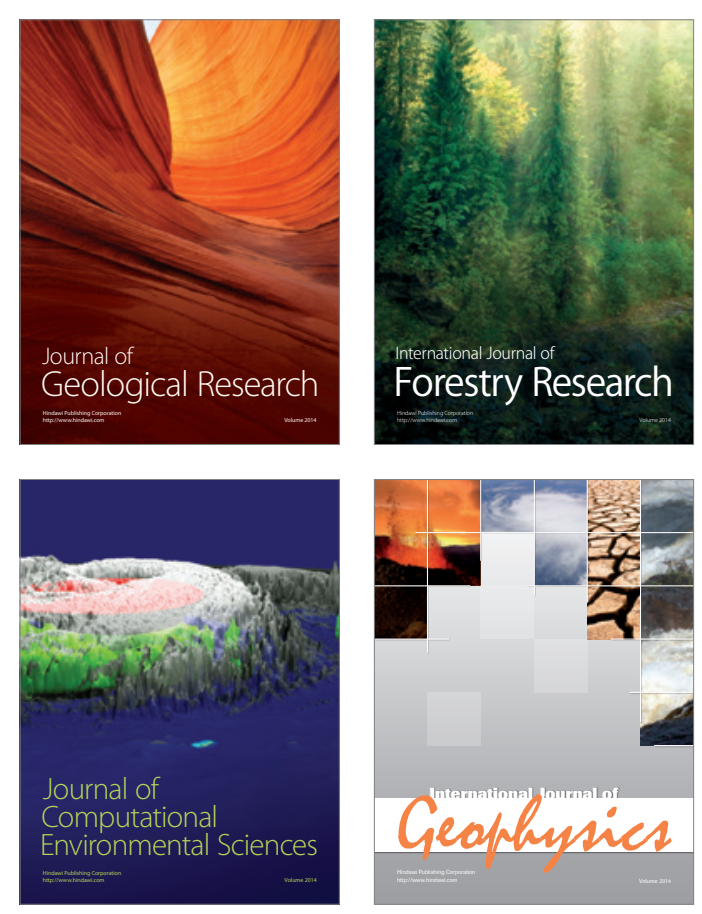
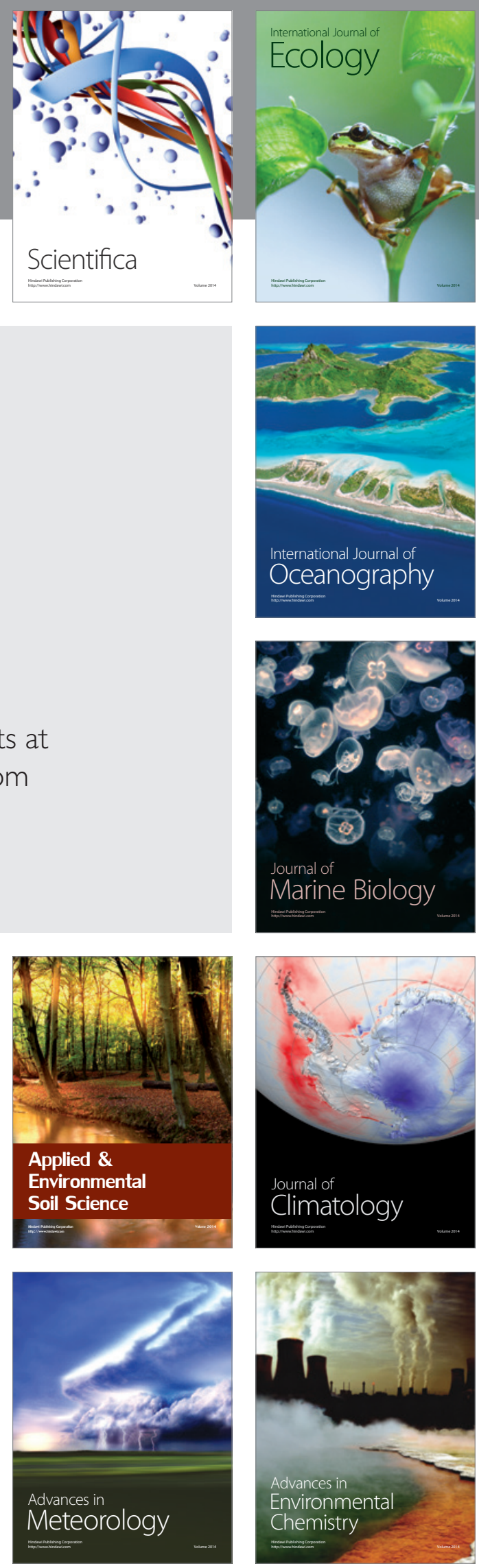